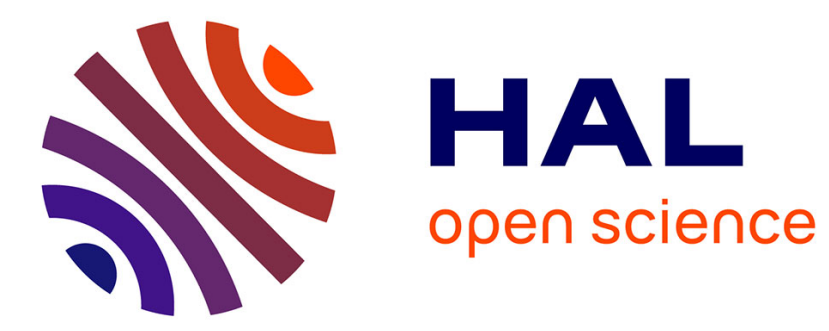

\title{
Mutual attraction of oscillating microbubbles
}

Michiel Postema, Michal Mleczko, Georg Schmitz

\section{To cite this version:}

Michiel Postema, Michal Mleczko, Georg Schmitz. Mutual attraction of oscillating microbubbles. Springer Proceedings in Physics, 2007, Advances in Medical Engineering, 114, pp.75-80. 10.1007/9783-540-68764-1_12 . hal-03192418

\section{HAL Id: hal-03192418 \\ https://hal.science/hal-03192418}

Submitted on 11 Apr 2021

HAL is a multi-disciplinary open access archive for the deposit and dissemination of scientific research documents, whether they are published or not. The documents may come from teaching and research institutions in France or abroad, or from public or private research centers.
L'archive ouverte pluridisciplinaire HAL, est destinée au dépôt et à la diffusion de documents scientifiques de niveau recherche, publiés ou non, émanant des établissements d'enseignement et de recherche français ou étrangers, des laboratoires publics ou privés. 


\title{
Mutual attraction of oscillating microbubbles
}

\author{
Michiel Postema ${ }^{1}$, Michał Mleczko ${ }^{1}$, and Georg Schmitz ${ }^{1}$ \\ ${ }^{1}$ Ruhr-Universität Bochum, Institute for Medical Engineering, Building IC, 6/144, 44780 \\ Bochum, Germany \\ E-mail: michiel.postema@ruhr-uni-bochum.de
}

\begin{abstract}
The driving of contrast microbubbles towards a boundary by means of primary radiation forces has been of interest for ultrasound-assisted drug delivery. Secondary radiation forces, resulting from oscillating microbubbles under ultrasound insonification, may cause the mutual attraction and subsequent coalescence of contrast microbubbles. This phenomenon has been less studied. Microbubbles with a negligible shell can be forced to translate towards each other at relatively low mechanical indices (MI). Thick-shelled microbubbles would require a higher MI to be moved. However, at high MI, microbubble disruption is expected. We investigated if thick-shelled contrast agent microbubbles can be forced to cluster at high-MI. The thick-shelled contrast agent M1639, inserted through a cellulose capillary, was subjected to $3 \mathrm{MHz}$, high-MI pulsed ultrasound from a commercial ultrasound machine, and synchronously captured through a high numerical aperture microscope. The agent showed the ultrasound-induced formation of bubble clusters, and the translation thereof towards the capillary boundary. Hence, forced translation and clustering of thick-shelled contrast microbubbles is feasible. The phase difference between the excursion of the oscillating bubble and the incident sound field was computed for free and encapsulated bubbles. There is a transition in phase difference for encapsulated bubbles, owing to the friction of the shell. Therefore, approach velocities of encapsulated bubbles may not be comparable to those of free gas bubbles.
\end{abstract}

\section{Introduction}

Translations of ultrasound contrast agent microbubbles in the direction of a sound field and toward each other have been frequently optically observed [1,2]. The driving of contrast microbubbles towards a boundary has been of interest for ultrasound-assisted drug delivery [3]. Microbubble translation in the direction of the sound field has been attributed to a primary radiation force resulting from a pressure gradient across the bubble surface. The translation is maximal in contraction phase. The velocity $v$ of a bubble in a steady fluid subjected to an ultrasound field can be expressed as [4]:

$$
F_{\mathrm{r}}+F_{\mathrm{d}}-\frac{\mathrm{d}(m v)}{\mathrm{d} t} \approx 0
$$

where $F_{\mathrm{r}}$ is the primary radiation force, $F_{\mathrm{d}}$ is the drag force, $m=(2 / 3) \pi \rho r_{0}{ }^{3}$ is the added mass of the translating bubble, equivalent to half the mass of the displaced surrounding fluid, in which $r_{0}$ is the ambient bubble radius and $\rho$ is the density of the surrounding fluid. Averaging over one acoustic cycle, the primary radiation force is given by $[1,4]$ : 


$$
F_{\mathrm{r}}=\frac{2 \pi r_{0} p_{\mathrm{a}}^{2}}{\omega \rho c} \frac{\delta \frac{\omega_{0}}{\omega}}{\left[\left(\frac{\omega_{0}}{\omega}\right)^{2}-1\right]^{2}+\left(\delta \frac{\omega_{0}}{\omega}\right)^{2}},
$$

where $c$ is the speed of sound, $p_{\mathrm{a}}$ is the peak rarefactional acoustic pressure, $\delta$ is the dimensionless total damping coefficient [5], $\omega$ is the angular driving frequency, and $\omega_{0}$ is the angular bubble resonant frequency [5].

The drag force is given by [4]:

$$
F_{\mathrm{d}}=-\frac{\pi \eta}{4} C_{\mathrm{d}} \operatorname{Re} r_{0} v(t)
$$

where $\eta$ is the shear viscosity of the fluid, $\operatorname{Re}=2 \rho r_{0}|v(t)| / \eta$ is the Reynolds number, and

$$
C_{\mathrm{d}}=\frac{24}{\operatorname{Re}}\left(1+0.15 \mathrm{Re}^{0.687}\right)
$$

is the drag coefficient of a contaminated system [6], such as a contrast agent.

Secondary radiation forces, resulting from oscillating microbubbles under ultrasound insonification, may cause the mutual attraction and subsequent coalescence of contrast microbubbles. This phenomenon has been less studied [2]. Two bubbles that oscillate in phase approach each other, whereas two bubbles that oscillate out of phase recede from each other [7,8]. At low acoustic amplitudes, the phase angle difference $\phi$ between excursion of the oscillating bubble and the incident sound field is given by $[7,8]$ :

$$
\phi=\arctan \left(\frac{\delta \frac{\omega}{\omega_{0}}}{1-\left(\frac{\omega}{\omega_{0}}\right)^{2}}\right)+\pi .
$$

The presence of an encapsulating shell increases the damping coefficient by a term $\delta_{\mathrm{s}}[9]$

$$
\delta_{\mathrm{s}}=\frac{S_{\mathrm{f}}}{m \omega}
$$

and the squared angular resonance frequency $\omega_{0}^{2}$ by a term $\omega_{s}^{2}[9]$

$$
\omega_{\mathrm{s}}^{2}=\frac{2 \chi}{r_{0}^{3} \rho},
$$

where $\chi$ is the shell stiffness parameter $[8,9]$

$$
\chi=\frac{\mathrm{E} \varepsilon}{1-v},
$$

in which $\mathrm{E}$ is Young's modulus, $\varepsilon$ is the shell thickness, and $v$ is the Poisson ratio. The mean approach velocity $v_{\mathrm{a}}$ of two identical bubbles is given by [1]: 


$$
v_{\mathrm{a}}=-\frac{\left(\omega p_{\mathrm{a}}\right)^{2}}{27 \eta} \rho \kappa^{2} \frac{r_{0}^{5}}{d_{0}^{2}},
$$

where $\kappa$ is the compressibility of the bubble, and $d_{0}$ is the distance between the centers of the two bubbles.

Microbubbles with a negligible shell can be forced to translate towards each other at relatively low mechanical indices (MI). Thick-shelled microbubbles would require a higher MI to be moved. However, at high MI, microbubble disruption is expected. We investigated if thick-shelled contrast agent microbubbles can be forced to cluster at high-MI.

\section{Experimental Methods}

Setup. The experimental setup designed for simultaneous optical and acoustical observations of ultrasound contrast agents has been described in [10]. In short, the thick-shelled contrast agent M1639 (POINT Biomedical Corporation, San Carlos, CA), inserted through a cellulose capillary, was subjected to $3 \mathrm{MHz}$, high-MI pulsed ultrasound from a Toshiba SSA-770A CV ultrasound machine (Toshiba Medical Systems Europe, Zoetermeer, The Netherlands), and synchronously captured with a WAT-902DM monochrome CCD camera (Watec Co., Ltd., Tsuruoka-Shi, Yamagata-Ken, Japan) through a high numerical aperture microscope (Olympus Deutschland GmbH, Hamburg, Germany).

The agent M1639 consists of bilayered microspheres encapsulating nitrogen bubbles with a mean radius of $2 \mu \mathrm{m}$. The shell thickness is proportional to the bubble diameter.

Simulations. The phase angle differences $\phi$ were computed for free and encapsulated microbubbles, assuming low excursion amplitudes. Radii were chosen $0.5<r_{0}<5.0 \mu \mathrm{m}$. Known shell stiffness and friction parameters of the ultrasound contrast agent Albune ${ }^{\circledR}$ were included.

\section{Results and Discussion}

Figure 1 shows shows an image sequence of M1639 microbubbles under high-MI insonification. The direction of the ultrasound beam is right-to-left. In frame 1, the microbubbles are distributed unevenly on the right-hand side of the frame. In frame 10 , two clusters have been formed. In the subsequent frames, these clusters travel in the direction of the ultrasound, owing to primary radiation forces.

The hexagons in frame 1 mark two microbubbles with $3 \mu \mathrm{m}$ diameters. There approach has been measured and computed with equation (9), assuming $\kappa=$ $5 \times 10^{-7} \mathrm{~m}^{2} \mathrm{~N}^{-1}$. The result is shown in Figure 2 . 


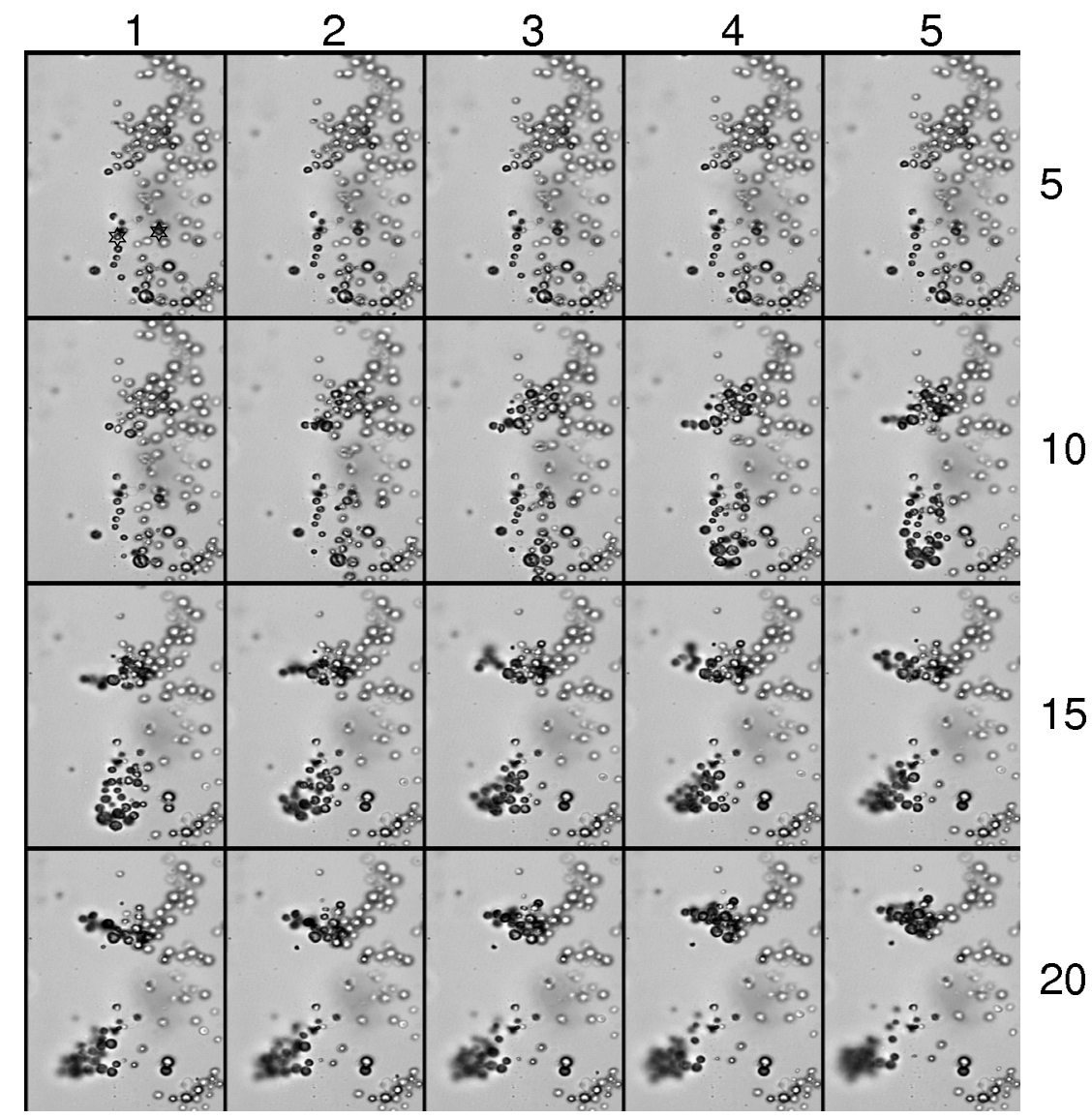

Fig. 1. M1639 microbubbles subjected to pulsed ultrasound from a commercial echo machine, operating at a $3 \mathrm{MHz}$ center frequency and a mechanical index $\mathrm{MI}=1.3$. Interframe time is $100 \mathrm{~ms}$. The frame corresponds to a $94.4 \times 70.8 \mu \mathrm{m}^{2}$ area. (C) 2006 IEEE. Reprinted with permission from [10].

The fact that the measured distances are lower than those computed has been attributed to the presence of surrounding bubbles.

It is remarkable that certain contrast agent microbubbles approach each other relatively quickly compared to others. Figure 3 offers a potential explanation. Free bubbles smaller than $1 \mu \mathrm{m}$ (below resonance) oscillate out of phase with the sound field, but in phase with each other, whereas microbubbles larger than $2 \mu \mathrm{m}$ (above resonance) oscillate in phase with the sound field and in phase with each other. For the contrast agent, the shell friction term causes a slow transition in phase difference, limiting the number of bubbles that oscillate exactly in or out of phase with each other. Identical bubbles, such as the bubbles indicated by the hexagons in Figure 1, therefore, may be expected to approach quickly, despite their distance. 


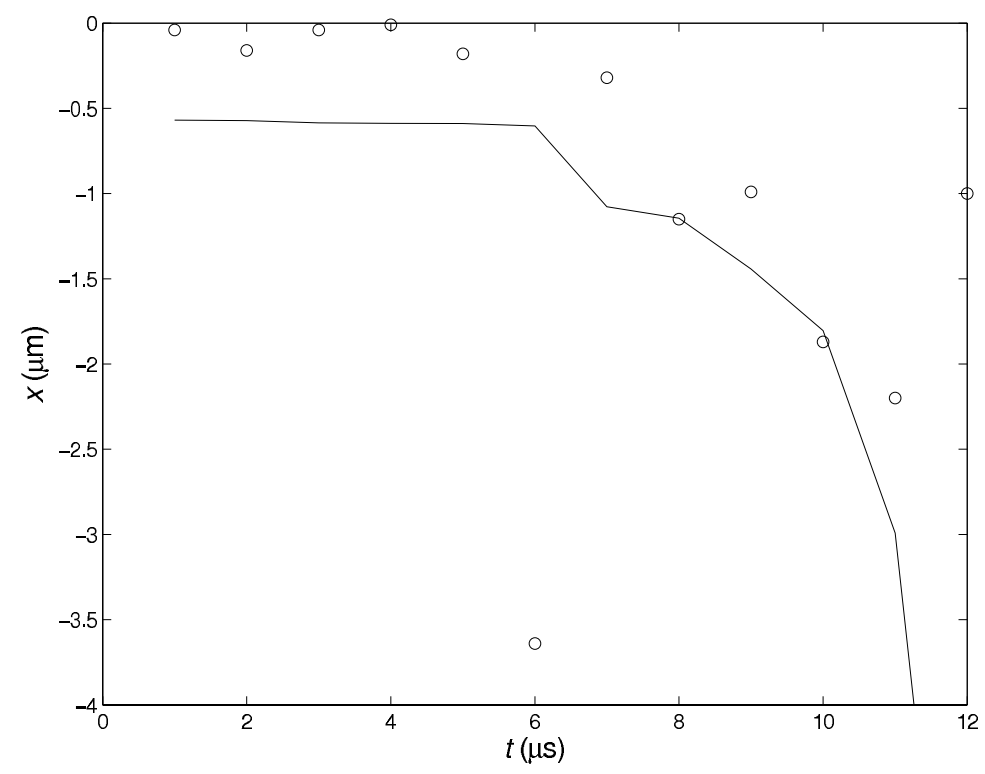

Fig. 2. Measured and computed traveled distances $x(t)$ of two identical $r_{0}=1.5 \mu \mathrm{m}$ M1639 microbubbles, assuming $\kappa=5 \times 10^{-7} \mathrm{~m}^{2} \mathrm{~N}^{-1}$. () 2006 IEEE. Reprinted with permission from [10].

\section{Conclusions}

The agent M1639 showed the ultrasound-induced formation of bubble clusters, and the translation thereof towards the capillary boundary. It is concluded, that forced translation and clustering of thick-shelled contrast microbubbles is feasible at high MI.

The phase difference between the excursion of the oscillating bubble and the incident sound field was computed for free and encapsulated bubbles. There is a transition in phase difference for encapsulated bubbles, owing to the friction of the shell. Therefore, approach velocities of encapsulated bubbles may not be comparable to those of free gas bubbles.

Acknowledgements. The authors are grateful to POINT Biomedical Corporation, San Carlos, CA, for supplying the contrast agent M1639. 


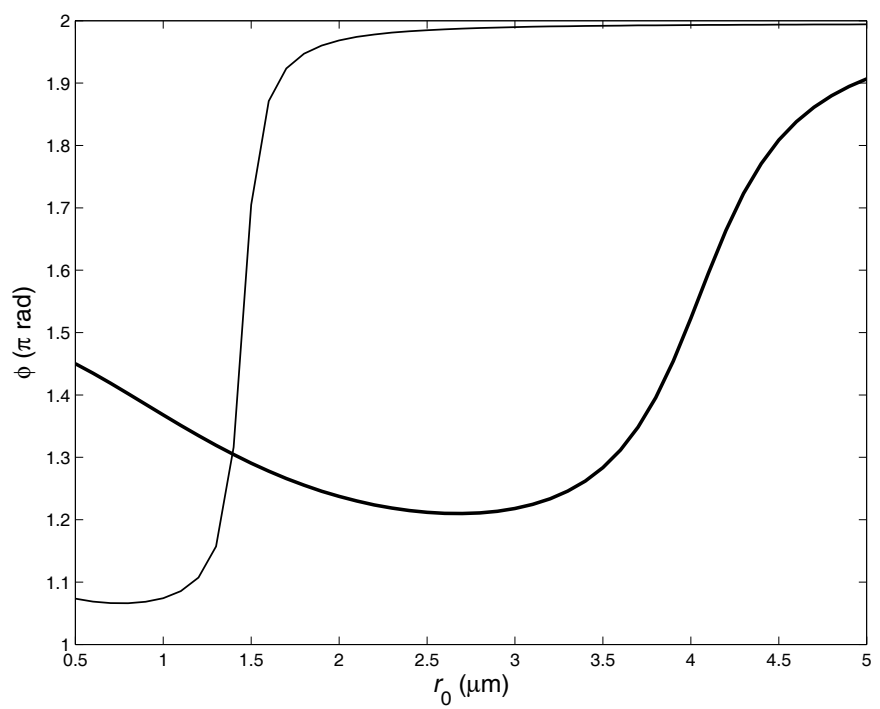

Fig. 3. Phase angle difference between a damped radially oscillating bubble and an incident $3 \mathrm{MHz}$ sound field, as a function of equilibrium microbubble radius $r_{0}$. The thin line represents a free bubble: $\chi=0 \mathrm{~kg} \mathrm{~s}^{-2}, S_{\mathrm{f}}=0 \mathrm{~kg} \mathrm{~s}^{-1}$, the bold line a hard-shelled microbubble: $\chi=10 \mathrm{~kg} \mathrm{~s}^{-2}, S_{\mathrm{f}}=4 \times 10^{-6} \mathrm{~kg} \mathrm{~s}^{-1}[9]$.

\section{References}

1 P. A. Dayton, K. E. Morgan, A. L. Klibanov, G. Brandenburger, K. R. Nightingale, and K. W. Ferrara, IEEE Trans. Ultrason., Ferroelect., Freq. Contr. 44, 1264, 1997.

2 M. Postema, A. van Wamel, C. T. Lancée, and N. de Jong, Ultrasound Med. Biol. 30, 827, 2004.

3 M. J. Shortencarier, P. A. Dayton, S. H. Bloch, P. A. Schumann, T. O. Matsunaga, and K. W. Ferrara, IEEE Trans. Ultrason., Ferroelect., Freq. Contr. 51, 822, 2004.

4 P. Tortoli, V. Michelassi, M. Corsi, D. Righi, and Y. Takeuchi, Ultrasound Med. Biol. 27, 1265, 2001.

5 H. Medwin, Ultrasonics 15, 7, 1977.

6 P. Di Marco, W. Grassi, and G. Memoli, Int. J. Therm. Sci. 42, 435, 2003.

7 F. R. Young, Cavitation. McGraw-Hill, Maidenhead, 1989.

8 M. Postema and G. Schmitz, Ultrason. Sonochem., in press, 2006.

9 N. de Jong, R. Cornet, and C. T. Lancée, Ultrasonics 32, 447, 1994.

10 M. Postema, M. Mleczko, and G. Schmitz, Proc. IEEE Ultrason. Symp., in press, 2006. 